\title{
Efeito do fornecimento de diferentes fontes de lipídeos na dieta sobre o consumo, a digestibilidade e o $\mathrm{N}$-uréico plasmático de novilhos bubalinos em confinamento
}

\author{
Ronaldo Lopes Oliveira1, Diêni Maria Pereira Assunção², Marco Aurélio Alves de Freitas \\ Barbosa $^{3}$, Márcio Machado Ladeira ${ }^{4}$, Manoel Messias Pereira da Silva ${ }^{3}$, Alessandra Gimenez \\ Mascarenhas ${ }^{3}$, Marília Viviane Snel-Oliveira ${ }^{3}$, Renata Lopes de Oliveira ${ }^{2}$
}

1 DPA/ESCMEV/UFBA, Salvador-BA.

2 Graduação em Zootecnia da UPIS, Brasília-DF.

${ }^{3}$ DZO/Faculdades Integradas UPIS, Brasília-DF.

${ }^{4}$ DZO/UFLA, Lavras-MG.

RESUMO - Este trabalho foi realizado com o objetivo de avaliar os efeitos de diferentes fontes de lipídeos sobre o consumo, a digestibilidade e o $\mathrm{N}$-uréico no plasma de novilhos bubalinos terminados em confinamento. Utilizaram-se 13 animais castrados Murrah $(297 \pm 9 \mathrm{~kg}$ de PV) alimentados com três diferentes dietas (tratamentos): sem lipídeo adicional; óleo de soja; e grão de soja integral. A duração do experimento foi de 84 dias, divididos em três períodos de coleta, cada um com 28 dias. Nos seis últimos dias de cada período, foram coletadas amostras de alimentos, sobras e fezes para análise e determinação do consumo e da digestibilidade. As rações foram fornecidas duas vezes ao dia, às 8 e 16h, na forma de ração total, em quantidade ajustada para ocorrer 10 a $20 \%$ de sobras. Verificou-se maior ingestão de MS e PB nos animais alimentados com a dieta sem lipídeo adicional, enquanto, com as dietas contendo óleo de soja e grão de soja integral, obteve-se maior ingestão de EE. Não foram verificados efeitos da adição de lipídeo sobre a digestibilidade da MS total, porém, os menores coeficientes de digestibilidade da fração fibrosa foram registrados nos animais alimentados com a dieta contendo óleo de soja. Os triglicerídeos presentes no grão de soja integral não tiveram esse efeito negativo, o que indica que estiveram menos disponíveis no rúmen. O aporte de energia com a inclusão de lipídeos provocou redução no consumo e, quando a fonte de energia foi o óleo de soja, diminuiu a digestibilidade das frações fibrosas das dietas.

Palavras-chave: búfalos, confinamento, grão de soja, óleo de soja

\section{Effect of different fat sources on intake, digestibility and blood urea nitrogen of feedlot water buffalo steers}

\begin{abstract}
The objective of this trial was to evaluate the effect of different dietary fat sources on intake, digestibility, and plasma urea $\mathrm{N}$ in feedlot water buffalo steers. Thirteen castrated Murrah steers averaging $297 \pm 9 \mathrm{~kg}$ of body weigh were assigned to one of the following three treatments: no added fat (control), soybean oil or whole soybean in a completely randomized design. The experiment lasted 84 days with three experimental periods of 28 days each. Samples of feeds, orts and feces were collected in the last six days of each period for determination of intake. Diets were fed twice a day ( 8 a.m. and 4 p.m.) as total mixed ration and the amount of feed offered was adjusted daily to yield refusals equal to approximately 10 to $20 \%$ of intake. Intakes of DM and CP were greater in the control compared to treatments supplemented with fat while the opposite was observed for ether extract intake. Apparent total tract digestibility of dry mater did not differ across treatments but animals fed the diet containing soybean oil had the lowest fiber digestibility. Feeding whole soybean to feedlot steers had no negative impact on fiber digestibility showing that the polyunsaturated fatty acids of this fat source were less available in the rumen. It can be concluded that the higher energy content of diets supplemented with fat sources increased DM intake but feeding soybean oil reduced fiber digestibility in this study.
\end{abstract}

Key Words: water buffaloes, feedlot, whole soybean, soybean oil

\section{Introdução}

A bubalinocultura tem se expandido no País e, com isso, tem crescido o interesse na terminação de novilhos em confinamento com o objetivo de elevar a eficiência alimentar e o ganho de peso, além de produzir carcaças de melhor qualidade (Jorge, 2004). Entretanto, para melhorar o desempenho animal e obter um produto de alta qualidade, deve-se

Correspondências devem ser enviadas para: ronaldooliveira @ufba.br 
fornecer aos animais alimentos que proporcionem alto consumo e adequada absorção de nutrientes.

Os fatores que primariamente regulam o consumo de alimentos pelos ruminantes são relacionados ao efeito direto da dieta, como: distensão da parede do rúmen, $\mathrm{pH}$ ruminal, concentração de ácidos orgânicos e metabolismo animal (Allen, 2000). De acordo com Thiago \& Gill (1990) e Van Soest (1994), existem dois fatores que limitam o consumo: a capacidade física do rúmen (quando se fornecem aos animais alimentos com baixas taxas de digestão) e a liberação de nutrientes no rúmen (quando os alimentos fornecidos possuem altas taxas de digestão).

Mertens (1997) descreveu ainda que o consumo é afetado pelas condições de alimentação (disponibilidade de alimento, espaço no cocho, tempo de acesso ao alimento, freqüência de alimentação, entre outros), pelas condições ambientais e, evidentemente, pelo teor de fibra e/ou energia da dieta. O consumo de MS em bubalinos pode ser afetado pelas características anatômicas e fisiológicas do trato gastrintestinal desses animais, que normalmente apresentam maior tempo de permanência do bolo alimentar no rúmen $\mathrm{e}$, conseqüentemente, menor taxa de passagem (Bhatia et al., 1979).

A utilização de fontes lipídicas na terminação de ruminantes é praticada há alguns anos no Brasil, sendo estudados seus efeitos sobre o desempenho animal, sua interação com outros nutrientes e a qualidade dos produtos animais. O principal desafio dos nutricionistas é elevar o nível lipídico das rações (sem alterar o consumo e a digestibilidade) e, conseqüentemente, aumentar a produtividade animal.

O lipídeo adicional na dieta de ruminantes serve para aumentar a ingestão energética. Entretanto, sua utilização pode ocasionar redução na degradabilidade da fibra pelas bactérias do rúmen. Desse modo, quando se deseja fornecer lipídeos na dieta de ruminantes, é importante avaliar seus efeitos sobre a ingestão e a digestão dos nutrientes, de modo a não prejudicar o aporte necessário para a produção desejada (Palmquist, 1994; Jenkins \& McGuire, 2006).

Quando ruminantes recebem fontes de gordura na dieta, os microrganismos do rúmen fazem com que ocorra a hidrólise dos triglicerídeos e a biohidrogenação dos ácidos graxos livres. Os lipídios, quando em excesso na dieta, podem afetar a digestão ruminal e o maior efeito é a redução da digestibilidade da fibra, da produção de metano e da relação acetato:propionato, principalmente se os níveis de ácidos graxos insaturados forem elevados (Hobson \& Stewart, 1997; Doreau \& Ferlay, 1995). Esses efeitos podem ser decorrentes das reduções no crescimento de bactérias (especialmente as celulolíticas/gram-positivas) e de protozoários (Tamminga \& Doreau, 1991) e do recobrimento físico da fibra com lipídeos (Hobson \& Stewart, 1997; Jenkins \& McGuire, 2006).

Os efeitos dos lipídeos da dieta sobre a digestão ruminal e total são de difícil predição e altamente variáveis, pois dependem da natureza e concentração lipídica da dieta, do tipo de tratamento dos alimentos e da natureza e quantidade de forragens, concentrados e minerais (principalmente cálcio) na dieta (Palmquist et al., 1986; Jenkins \& McGuire, 2006).

Como conseqüência dessas complexas interações, os efeitos metabólicos da suplementação de lipídios na dieta não podem ser analisados como um resultado simples do aumento de absorção pelo intestino de ácidos graxos intactos (ou ruminalmente transformados) da dieta.

A uréia é a forma primária pela qual os mamíferos excretam o nitrogênio e a concentração de uréia plasmática reflete a utilização da PB em ruminantes (Valadares et al., 1999; Marini \& Van Amburgh, 2003). O excesso de nitrogênio pode prejudicar o desempenho reprodutivo e aumentar as exigências de energia, pois são necessários $13,3 \mathrm{kcal}$ de energia digestível para excreção de $1 \mathrm{~g}$ de nitrogênio. Ressalta-se que o excesso de uréia pode causar toxicidade nos animais, em virtude da alcalose sistêmica metabólica e, em grande parte, da intoxicação do sistema nervoso central pela amônia (Swenson \& Reece, 1993).

Existe maior correlação entre amônia ruminal e uréia plasmática em búfalos, visto que esses animais possuem eficientes mecanismos de reciclagem da uréia, que pode ser melhor aproveitada pelos microrganismos para sintetizar aminoácidos (Bhatia et al.,1979; Lundri \& Razdan, 1980).

Segundo Swenson \& Reece (1993), normalmente o $\mathrm{N}$-uréico sangüíneo de bovinos situa-se entre 10 e $30 \mathrm{mg} / \mathrm{dL}$ no plasma, contudo, em búfalos esses valores ainda não estão bem estabelecidos na literatura.

Nesta pesquisa objetivou-se avaliar os efeitos da utilização de grão ou óleo de soja na dieta sobre o consumo, a digestibilidade e o $\mathrm{N}$-uréico plasmático de novilhos bubalinos terminados em confinamento.

\section{Material e Métodos}

O experimento foi realizado na Fazenda Lagoa Bonita Campus Rural das Faculdades UPIS, em Planaltina-DF, no período de setembro a dezembro de 2003. Foram utilizados 13 novilhos bubalinos castrados Murrah, com 15 meses de idade e peso vivo inicial de $297 \pm 9 \mathrm{~kg}$. Antes do experimento, os animais foram pesados, vermifugados e distribuídos aleatoriamente em três tratamentos. As dietas foram formu- 
ladas com silagem de milho como volumoso e milho grão moído, farelo de soja, grão de soja integral e óleo de soja como ingredientes dos concentrados. As amostras dos alimentos foram colhidas durante todo o período experimental para análises bromatológicas (Tabela 1).

Foram utilizados três tratamentos: sem lipídeo adicional; grão de soja integral; e óleo de soja. A proporção dos ingredientes nas rações e seus valores nutricionais são apresentados nas Tabelas 2 e 3, respectivamente.

A duração do experimento foi de 84 dias, divididos em três períodos de coleta, cada um com 28 dias. Nos seis últimos dias de cada período, foram coletadas amostras de alimentos, sobras e fezes. Os animais foram pesados no início do experimento e ao fim de cada período experimental, depois de jejum de 16 horas. Os animais foram confinados individualmente em baias de madeira com $24 \mathrm{~m}^{2}$ em piso batido ( $12 \mathrm{~m}^{2}$ cobertos de telha em fibrocimento). A alimen-

\begin{tabular}{lcccc} 
Tabela 1 - Composição bromatológica dos ingredientes das \\
dietas $(\%)^{1}$ \\
Table 1 - & Chemical composition of dietary ingredients \\
\hline Nutriente & $\begin{array}{c}\text { Silagem de } \\
\text { milho }\end{array}$ & $\begin{array}{c}\text { Milho } \\
\text { grão }\end{array}$ & $\begin{array}{c}\text { Farelo de } \\
\text { soja }\end{array}$ & $\begin{array}{c}\text { Grão de soja } \\
\text { integral }\end{array}$ \\
& Corn & Corn & Soybean & Whole \\
& silage & grain & meal & soybean \\
\hline MS (DM) (\%) & 32,74 & - & - & - \\
PB (CP) (\%) & 12,60 & 8,32 & 42,80 & 35,77 \\
FDN (NDF) (\%) & 52,63 & 13,55 & 21,12 & 25,56 \\
FDA (ADF) (\%) & 34,34 & 4,03 & 11,90 & 19,72 \\
EE (\%) & 2,96 & 4,74 & 1,50 & 19,55 \\
CNF (NFC) (\%) & 24,01 & 71,82 & 31,17 & 14,55 \\
LIG (\%) & 7,04 & 0,97 & 2,69 & 6,93 \\
\hline
\end{tabular}

${ }^{1}$ Análises realizadas no Laboratório de Análise de Alimentos da UPIS. ${ }^{1}$ Analysis were done at the UPIS Feed Analysis Laboratory.

Tabela 2 - Proporção dos ingredientes nas dietas (\%MS)

\begin{tabular}{lccc}
\hline $\begin{array}{l}\text { Ingrediente } \\
\text { Ingredient }\end{array}$ & \multicolumn{3}{c}{$\begin{array}{c}\text { Tratamento } \\
\text { Treatment }\end{array}$} \\
\cline { 2 - 4 } & $\begin{array}{c}\text { Sem lipídeo } \\
\text { adicional } \\
\text { No added } \\
\text { fat }\end{array}$ & $\begin{array}{c}\text { Grão de soja } \\
\text { integral } \\
\text { Whole } \\
\text { soybean }\end{array}$ & $\begin{array}{c}\text { Óleo de } \\
\text { soja } \\
\text { Soybean } \\
\text { oil }\end{array}$ \\
\hline $\begin{array}{l}\text { Silagem de milho } \\
\text { Corn silage }\end{array}$ & 60,00 & 60,00 & 60,00 \\
$\begin{array}{l}\text { Milho grão } \\
\text { Corn grain }\end{array}$ & 35,17 & 26,41 & 32,09 \\
$\begin{array}{l}\text { Farelo de soja } \\
\text { Soybean meal } \\
\text { Grão de soja integral }\end{array}$ & 3,71 & - & 4,28 \\
$\begin{array}{l}\text { Whole soybean } \\
\text { Óleo de soja } \\
\text { Soybean oil }\end{array}$ & - & 13,59 & - \\
$\begin{array}{l}\text { Uréia } \\
\text { Urea }\end{array}$ & - & - & 2,50 \\
\hline
\end{tabular}

Tabela 3 - Composição bromatológica (\%MS) das dietas ${ }^{1}$ Table 3 - Chemical composition of the experimental diets (\% of DM)

\begin{tabular}{|c|c|c|c|}
\hline \multirow[t]{2}{*}{$\begin{array}{l}\text { Nutriente } \\
\text { Nutrient }\end{array}$} & \multicolumn{3}{|c|}{$\begin{array}{c}\text { Tratamento } \\
\text { Treatment }\end{array}$} \\
\hline & $\begin{array}{c}\text { Sem lipídeo } \\
\text { adicional } \\
\text { No added } \\
\text { fat }\end{array}$ & $\begin{array}{c}\text { Grão de soja } \\
\text { integral } \\
\text { Whole } \\
\text { soybean }\end{array}$ & $\begin{array}{l}\text { Óleo de } \\
\text { soja } \\
\text { Soybean } \\
\text { oil }\end{array}$ \\
\hline $\mathrm{PB}(C P)$ & 11,93 & 11,58 & 11,93 \\
\hline $\mathrm{FDN}(N D F)$ & 38,54 & 41,01 & 38,20 \\
\hline FDA $(A D F)$ & 23,55 & 27,20 & 23,44 \\
\hline $\mathrm{EE}(E E)$ & 3,92 & 5,54 & 6,21 \\
\hline $\mathrm{CNF}(N F C)$ & 42,31 & 37,31 & 40,47 \\
\hline Cinzas (Ash) & 3,31 & 4,57 & 3,19 \\
\hline
\end{tabular}

${ }^{1}$ Análises realizadas no Laboratório de Análise de Alimentos da UPIS.

${ }^{1}$ Analysis were done at the UPIS Feed Analysis Laboratory.

tação foi fornecida em cochos de PVC ( 3 m lineares/animal) e a água (à vontade), em bebedouro localizado na área descoberta das instalações. A dieta foi fornecida duas vezes ao dia (às 8 e 16h), na forma de ração total, misturada e ajustada para manter as sobras em torno de 10 a $20 \%$ do oferecido. No período da manhã, durante os últimos seis dias de cada período experimental, foram retiradas e pesadas as sobras para determinação do consumo e cálculo da conversão alimentar.

As análises dos teores de MS, MO, PB e EE foram realizadas no Laboratório de Análises de Alimentos do Departamento de Zootecnia da UPIS, de acordo com a AOAC (1990). As concentrações de fibra em detergente neutro corrigida para cinzas e proteína (FDNcp) e de FDA foram analisadas segundo Goering \& Van Soest (1970) e o FDNcp dos concentrados, segundo procedimento descrito por Van Soest et al. (1991).

A determinação dos CNF foi realizada segundo o NRC (2001), por meio da expressão: $\mathrm{CNF}=[100-(\% \mathrm{~PB}+\% \mathrm{FDNcp}$ $+\% \mathrm{EE}+\%$ Cinzas) $]$.

A produção fecal foi estimada utilizando-se o FDNcp indigestível in situ, determinado em $5 \mathrm{~g}$ de amostras dos alimentos, das fezes e das sobras, que foram colocadas em sacos de náilon e incubadas (144 horas) em búfalas fistuladas no rúmen, segundo metodologia descrita por Cochran et al. (1986). A partir destes dados, foram calculados os consumos de NDT e as digestibilidades aparentes de MS, PB, FDN, FDA, EE e CNF.

A coleta de sangue foi realizada ao fim de cada período, utilizando-se agulha e tubo para armazenagem do sangue extraído da veia jugular ( $10 \mathrm{~mL})$ com o animal contido em brete. A primeira coleta foi realizada com o animal em jejum e as demais (em intervalos de duas horas), sem a restrição alimentar, totalizando quatro amostras por animal por período. 
As amostras de sangue foram encaminhadas imediatamente ao laboratório de análise de alimentos do Departamento de Zootecnia da UPIS, onde foram centrifugadas para separação do plasma e obtenção das concentrações plasmáticas de uréia. O teor de $\mathrm{N}$-uréico foi determinado em aparelho espectofotômetro utilizando-se o protocolo de kits enzimáticos comerciais considerando o pressuposto de que a uréia plasmática contém $46 \%$ de $\mathrm{N}$.

$\mathrm{O}$ delineamento experimental foi o inteiramente ao acaso, com repetições no tempo (período) utilizando-se como covariável o peso inicial a cada período. Para os teores de $\mathrm{N}$-uréico, adotou-se o esquema de parcelas subdivididas no qual as dietas foram as parcelas e o tempo após a alimentação, as subparcelas. Os dados foram avaliados por meio de análise de variância e as médias, pelo teste Tukey a $5 \%$ de probabilidade.

\section{Resultados e Discussão}

As médias encontradas para os consumos de MS, PB, FDNcp, FDA, EE e CNF, expressos em kg/dia e \%PV, são descritas na Tabela 4.

O consumo de EE pelos animais alimentados com a dieta contendo grão de soja integral e óleo de soja foi maior que o daqueles do tratamento sem lipídeo adicional, o que era esperado, pois este era o objetivo da pesquisa. Essa maior ingestão de lipídeos provocou menores consumos (em kg por dia) de MS, PB e CNF pelos animais que receberam as dietas com grão de soja integral e óleo de soja. Esse resultado pode ser explicado pelo atendimento energético que possivelmente ocorreu com o aporte de lipídeos na alimentação dos búfalos, explicado pela teoria de regulação do consumo pela energia, descrita por Thiago \& Gill (1990) e Van Soest (1994).

Vargas et al. (2001) relataram que, ao elevar o teor de lipídeos da dieta, pode ocorrer maior aporte de energia. Assim, automaticamente, esse excedente de energia é direcionado para o acúmulo de gordura. Quando começa a ocorrer esse acúmulo de gordura significa que os teores de metabólitos energéticos no sangue do animal estão elevados, o que ativa o centro da saciedade e inibe o da fome, ambos localizados no hipotálamo.

À exceção do consumo de PB (\%PV), que não diferiu entre os tratamentos, o consumo dos nutrientes em porcentagem do peso vivo não diferiu do consumo em valores absolutos. Pode-se inferir então que, apesar de os animais consumirem quantidades absolutas diferentes, adequaram seus processos fisiológicos de modo a atender sua necessidade protéica em \%PV. Como o trabalho foi realizado com
Tabela 4 - Consumos médios das dietas Table 4 - Average intake of nutrients

\begin{tabular}{|c|c|c|c|c|}
\hline \multirow{2}{*}{$\begin{array}{l}\text { Nutriente } \\
\text { Nutrient }\end{array}$} & \multicolumn{3}{|c|}{$\begin{array}{c}\text { Tratamento } \\
\text { Treatment }\end{array}$} & \multirow[t]{2}{*}{$\mathrm{CV}(\%)$} \\
\hline & $\begin{array}{c}\text { Sem lipídeo } \\
\text { adicional } \\
\text { No added } \\
\text { fat }\end{array}$ & $\begin{array}{c}\text { Grão de soja } \\
\text { integral } \\
\text { Whole } \\
\text { soybean }\end{array}$ & $\begin{array}{l}\text { Óleo de } \\
\text { soja } \\
\text { Soybean } \\
\text { oil }\end{array}$ & \\
\hline & \multicolumn{3}{|c|}{$\mathrm{kg} / \mathrm{animal} / \mathrm{dia}$ (kg/animal/day) } & \\
\hline $\operatorname{MS}(D M)$ & $8,62^{\mathrm{a}}$ & $8,30^{\mathrm{b}}$ & $7,64^{\mathrm{b}}$ & 9,30 \\
\hline $\mathrm{PB}(C P)$ & $1,41^{\mathrm{a}}$ & $1,32^{b}$ & $1,26^{b}$ & 8,30 \\
\hline FDN $(N D F)$ & $2,98^{\mathrm{a}}$ & $3,12^{\mathrm{a}}$ & $2,55^{b}$ & 11,27 \\
\hline FDA $(A D F)$ & $1,83^{\mathrm{b}}$ & $2,16^{\mathrm{a}}$ & $1,58^{\mathrm{c}}$ & 10,88 \\
\hline $\mathrm{EE}(E E)$ & $0,37^{b}$ & $0,54^{\mathrm{a}}$ & $0,57^{\mathrm{a}}$ & 7,65 \\
\hline \multirow[t]{2}{*}{$\mathrm{CNF}(N F C)$} & $3,53^{\mathrm{a}}$ & $2,86^{\mathrm{b}}$ & $2,96^{b}$ & 8,82 \\
\hline & \multicolumn{3}{|c|}{$\%$ do $\mathrm{PV}(\%$ of $B W)$} & \\
\hline $\operatorname{MS}(D M)$ & $2,62^{\mathrm{a}}$ & $2,47^{\mathrm{b}}$ & $2,34^{\mathrm{b}}$ & 8,71 \\
\hline $\mathrm{PB}(C P)$ & $0,40^{\mathrm{a}}$ & $0,42^{\mathrm{a}}$ & $0,39^{\mathrm{a}}$ & 7,94 \\
\hline FDN $(N D F)$ & $0,85^{\mathrm{b}}$ & $0,99^{\mathrm{a}}$ & $0,78^{\mathrm{b}}$ & 10,55 \\
\hline FDA, $(A D F)$ & $0,53^{\mathrm{b}}$ & $0,68^{\mathrm{a}}$ & $0,48^{\mathrm{b}}$ & 10,24 \\
\hline $\mathrm{EE}(E E)$ & $0,11^{\mathrm{b}}$ & $0,17^{\mathrm{a}}$ & $0,18^{\mathrm{a}}$ & 8,33 \\
\hline $\mathrm{CNF}(\mathrm{NFC})$ & $1,01^{\mathrm{a}}$ & $0,90^{\mathrm{b}}$ & $0,91^{\mathrm{b}}$ & 8,34 \\
\hline
\end{tabular}

a, b Médias seguidas de mesma letra, na linha, não diferem estatisticamente pelo teste Tukey $(P>0,05)$.

a, b Means followed by the same letter, in the same row, do not differ by Tukey test $(P>0.05)$.

diferentes fontes de energia na forma de lipídeos, é possível que, depois de atendida a exigência de energia, o animal tenha consumido para atender à exigência de proteína, um nutriente de extrema importância para mantença e ganho.

As médias encontradas para as digestibilidades totais de MS, PB, FDNcp, FDA, EE e CNF são expressas na Tabela 5.

Não foram verificados efeitos da adição de óleo nas dietas sobre a digestibilidade da MS. No entanto, a inclusão do óleo de soja nas dietas influenciou de forma negativa as digestibilidades da FDN e FDA. É possível que a redução na digestibilidade dos carboidratos fibrosos no tratamento com óleo de soja não tenha afetado a digestibilidade total da MS, haja vista o aumento nas digestibilidades da PB, EE e CNF obtido com este tratamento.

$\mathrm{Na}$ dieta com óleo de soja, os ácidos graxos estavam mais prontamente disponibilizados no rúmen, o que pode ter causado redução na digestibilidade da FDN. Palmquist (1994) e Hobson \& Stewart (1997) relataram que este mecanismo pode se refletir de diversas formas, como pela cobertura física da fibra dietética, impedindo o ataque dos microrganismos, pela modificação da população microbiana do rúmen, como resultado do efeito tóxico do lipídeo sobre os microrganismos ruminais e dos efeitos ativos da gordura da dieta na superfície das membranas dos microrganismos, mais aceito na atualidade (Jenkins \& McGuire, 2006).

Não foi possível observar diminuição na digestibilidade das frações fibrosas das dietas contendo grão de soja integral, 
Tabela 5 - Digestibilidade dos nutrientes das dietas (\%) Table 5 - $\quad$ Apparent total tract digestibility of nutrients (\%)

\begin{tabular}{|c|c|c|c|c|}
\hline \multirow[t]{2}{*}{$\begin{array}{l}\text { Nutriente } \\
\text { Nutrient }\end{array}$} & \multicolumn{3}{|c|}{$\begin{array}{c}\text { Tratamento } \\
\text { Treatment }\end{array}$} & \multirow[t]{2}{*}{$\mathrm{CV}(\%)$} \\
\hline & $\begin{array}{c}\text { Sem lipídeo } \\
\text { adicional } \\
\text { No added } \\
\text { fat }\end{array}$ & $\begin{array}{c}\text { Grão de soja } \\
\text { integral } \\
\text { Whole } \\
\text { soybean }\end{array}$ & $\begin{array}{l}\text { Óleo de } \\
\text { soja } \\
\text { Soybean } \\
\text { oil }\end{array}$ & \\
\hline $\operatorname{MS}(D M)$ & 63,88 & 61,62 & 63,85 & 5,87 \\
\hline $\mathrm{PB}(C P)$ & $71,73^{\mathrm{ab}}$ & $68,67^{b}$ & $75,01^{\mathrm{a}}$ & 4,85 \\
\hline FDN $(N D F)$ & $41,31^{\mathrm{a}}$ & $39,50^{a b}$ & $33,53^{b}$ & 17,47 \\
\hline FDA $(A D F)$ & $37,50^{\mathrm{ab}}$ & $42,46^{\mathrm{a}}$ & $32,66^{b}$ & 20,23 \\
\hline $\mathrm{EE}(E E)$ & $85,01^{b}$ & $86,42^{b}$ & $90,36^{\mathrm{a}}$ & 3,15 \\
\hline $\mathrm{CNF}(N F C)$ & $81,77^{a b}$ & $80,08^{b}$ & $83,00^{\mathrm{a}}$ & 3,06 \\
\hline
\end{tabular}

possivelmente em razão da lenta liberação dos triglicerídeos presentes no interior das células dos grãos de oleaginosas (Tamminga \& Doreau, 1991; Doreau \& Ferlay, 1995).

A porcentagem de NDT nas dietas sem lipídeo adicional $(67,69 \%)$ não foi estatisticamente diferente daquela consumida na presença do grão de soja, que, por sua vez, foi em torno de $65,85 \%$ na MS. Contudo, os animais que consumiram a dieta acrescida de óleo ingeriram maiores concentrações de NDT em comparação às outras dietas $(\mathrm{P}<0,05)$. A concentração percentual de NDT na MS da dieta com óleo de soja $(71,15)$ foi mais alta, provavelmente em virtude da maior digestibilidade do EE e dos CNF.

É necessário avaliar, no entanto, a viabilidade da adição de óleo, que pode significar utilização menos eficiente da fração fibrosa. Entretanto, mesmo com a redução na digestibilidade da fração fibrosa, é possível atender ou até elevar a quantidade de energia ou NDT disponível para o animal, como demonstrado neste experimento. Portanto, apenas o fator financeiro influencia na decisão acerca da utilização deste produto na terminação de bubalinos em confinamento.

Na Figura 1 são representadas graficamente as concentrações de N-uréico no plasma sangüíneo dos novilhos após o consumo das rações.

As concentrações médias de N-uréico plasmático foram de 11,90; 15,04 e 15,38 mg/100 mL nos animais alimentados com as dietas sem lipídeo adicional, com grão de soja integral e com óleo de soja, respectivamente, não havendo diferenças estatísticas entre os dois últimos tratamentos $(\mathrm{P}>0,05)$. A menor concentração de $\mathrm{N}$-uréico plasmático com a dieta sem lipídeo adicional $(\mathrm{P}<0,05)$ sugere que a maior presença de CNF característica dessa dieta levou à melhor sincronização com a degradação da proteína no rúmen dos novilhos bubalinos.

De acordo com as equações da Figura 1, foram estimados os pontos de máximo de $\mathrm{N}$-uréico plasmático e o tempo
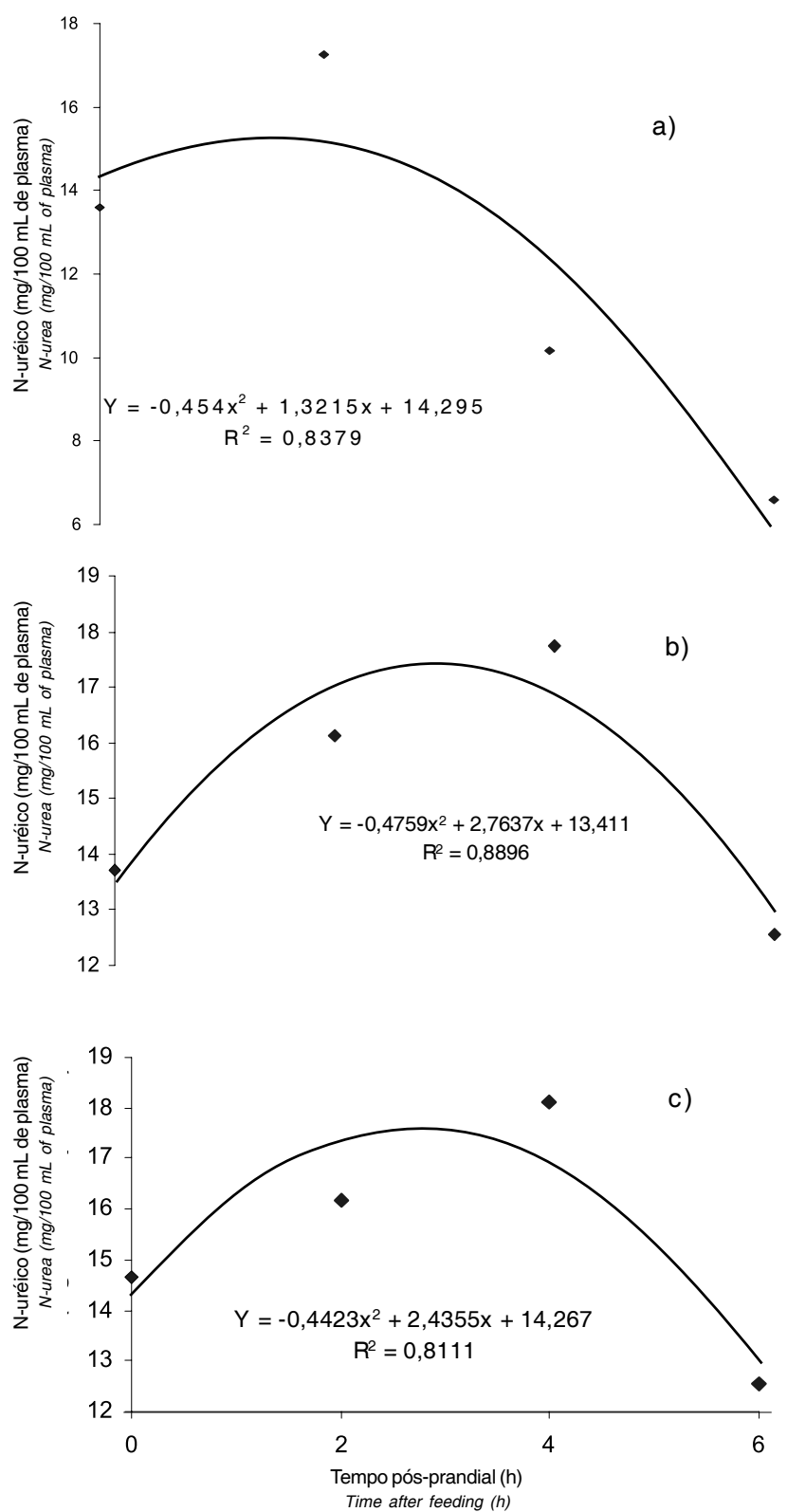

Figura 1 - N-uréico plasmático (mg/100 mL): a) Sem lipídeo adicional; b) grão de soja integral; c) óleo de soja.

Figure 1 - Plasma concentration of urea ( $\mathrm{mg} / 100 \mathrm{~mL})$ : a) no added fat b) whole soybean; c) soybean oil.

em que estes pontos ocorreram nos diversos tratamentos. No tratamento sem lipídeo adicional, o ponto máximo foi de $15,26 \mathrm{mg} / 100 \mathrm{~mL}$ e ocorreu 1,46 horas após a alimentação; a dieta com grão de soja integral proporcionou valores máximos de 17,42 mg/100 mL 2,90 horas pós-prandial; e, para aquela com óleo de soja, o ponto máximo foi de 17,62 mg/ $100 \mathrm{~mL}$ e ocorreu 2,75 horas após a alimentação.

A dieta sem lipídeo adicional apresentou teor médio e ponto de máximo de N-Uréico inferior ao daquelas com grão de soja integral e óleo de soja. Além disso, o pico ocorreu mais rapidamente e a redução nos níveis de $\mathrm{N}$-uréico também foi mais acentuada. Esses resultados sugerem 
melhor sincronia entre energia e proteína no rúmen para a dieta sem lipídeo adicional, provavelmente em virtude da maior concentração de CNF.

Os maiores teores médios de $\mathrm{N}$-uréico e o ponto de máxima na dieta sem lipídeo adicional podem também ser explicados pelo efeito prejudicial dos lipídeos sobre o crescimento das bactérias celulolíticas, visto que estas bactérias utilizam o N-NH $\mathrm{N}_{3}$ como fonte de proteína para seu crescimento (Goodrich et al., 1984; Lana \& Fox, 2001). Como esses microrganismos provavelmente tiveram o crescimento afetado, houve acúmulo amoniacal no rúmen e uréico no plasma.

Valadares et al. (1997) concluíram que concentrações de N-Uréico de 13,5 a 15,15 mg/100 mL corresponderam à máxima eficiência microbiana ou à mínima perda protéica em novilhos bovinos em confinamento. Nesta pesquisa, foram observados valores superiores aos encontrados por esses autores, o que permite inferir que, nas dietas com óleo de soja e grão de soja integral, pode ter ocorrido perda de $\mathrm{N}$ dietético.

\section{Conclusões}

Nos novilhos bubalinos, o aporte de energia com a inclusão de lipídeos provocou redução no consumo. Quando esta fonte de energia foi o óleo de soja, houve diminuição da digestibilidade das frações fibrosas das dietas.

Em recomendações quanto ao uso ou não desses ingredientes em dietas para bubalinos, devem ser consideradas as variáveis econômicas e de desempenho produtivo.

\section{Literatura Citada}

ASSOCIATION OF ANALYTICAL CHEMISTS - AOAC. Official methods of analysis. 12.ed. Washington, D.C.: 1990. 1094p.

ALLEN, M.S. Effects of diet on short-term regulation of feed intake by lactating dairy cattle. Journal of Dairy Science, v.83, p.1598, 2000.

BHATIA, S.K.; PRADHAN, K.; SINGH, R. et al. A note on relative efficiency of feed intake and digestibility in cattle and buffaloes. Indian Journal of Animal Science, v.49, p.468-470, 1979.

COCHRAN, R.C.; ADAMS, D.C.; WALLACE, J.D. et al. Predicting digestibility diets with internal markers: Evaluation of four potential markers. Journal of Animal Science, v.63, p.14761483, 1986

DOREAU, M.; FERLAY, A. Effect of dietary lipids on nitrogen metabolism in the rumen: a review. Livestock Production Science, v.43, p.97-110, 1995.

GOERING, H.K.; van SOEST, J.P. Forage fiber analysis (apparatus reagents, procedure, and some applications). Washington, D.C.: Agriculture Handbook, ARS, USDA, 1970. p. 379 .

GOODRICH, R.D.; GARRETT, J.E.; GAST, D.R. et al. Influence of monensin on the performance of cattle. Journal of Animal Science, v.58, p.1484-1498, 1984.
HOBSON, P.N.; STEWART, C.S. The rumen microbial ecosystem. London: Blackie Academic and Professional, 1997. 340 .

JENKINS, T.C.; McGUIRE, M.A. Major advances in nutrition: impact on milk composition. Journal of Dairy Science, v.89, p.1302-1310, 2006.

JORGE, A.M. Produção de carne bubalina. In: OLIVEIRA, R.L. (Ed.) A Zootecnia e o agronegócio. 1.ed. Brasília: Gráfica e Editora Inconfidência, 2004. v.1, p.617-634.

LANA, R.P.; FOX, D.G. Interações entre monensina sódica, óleo de soja e fontes de nitrogênio no desempenho de novilhos Aberdeen Angus em confinamento. Revista Brasileira de Zootecnia, v.30, p.247-253, 2001.

LUNDRI, R.S.; RAZDAN, M.N. Efficiency of nitrogen utilization by zebu cows and buffaloes. I- Nutrient utilizations and nitrogen balance and performed protein diets. Tropical Agriculture, v. 57, p.123-131, 1980.

MARINI , J.C.; van AMBURGH, M.E. Nitrogen metabolism and recycling in Holstein heifers. Journal of Animal Science, v. 81, p. $545-552,2003$.

MERTENS, D.R. Creating a system for meeting the fiber requirements of dairy cows. Journal of Dairy Science, v. 80 , p.1463-1481, 1997.

NATIONAL RESEARCH COUNCIL - NRC. Nutrient requirements of dairy cattle. 7.rev.ed. Washington, D.C.: National Academic Press, 2001. 242p.

PALMQUIST, D.L. The role of dietary fats in efficiency of ruminants. Conference: regulating lipids metabolism to increase productive efficiency. Journal of Nutrition, v.124, p.13771382, 1994.

PALMQUIST, D.L.; JENKINS, T.C.; JOYNER JR., A.E. Effect of dietary fat and calcium source on insoluble soap formation in the rumen. Journal of Dairy Science, v.69, p.1020-1025, 1986.

SWENSON, M.J.; REECE, W. Dukes: fisiologia dos animais domésticos. 11.ed. Rio de Janeiro: Guanabara Koogan, 1993. $338 \mathrm{p}$.

TAMMINGA, S.; DOREAU, M. Lipids and rumen digestion. In: JOUANY, J.P. (Ed.) Rumen microbial metabolism and ruminant digestion. Paris: Institut National de la Recherche Agronomique, 1991.p.151-164.

THIAGO, L.R.L.; GILL, S. Consumo voluntário: fatores relacionados com a degradação e passagem da forragem pelo rúmen. Campo Grande: EMBRAPA - CNPGC, 1990. 32p.

VALADARES, R.F.D.; GONÇALVES, L.C.; RODRIGUEZ, N.M. et al. Níveis de proteína em dietas de bovinos. 4. Concentração de amônia ruminal e uréia plasmática e excreções de creatina. Revista Brasileira de Zootecnia, v.26, p.1270-1278, 1997.

VALADARES, R.F.D.; BRODERICK, G.A.; VALADARES FILHO, S.C. et al. Effect of replacing alfalfa with high moisture corn on ruminal protein synthesis estimated from excretion of total purine derivatives. Journal of Dairy Science, v.82, p.26862696, 1999.

Van SOEST, P.J. Nutritional ecology of the ruminant. 2.ed. Ithaca: Cornel University Press, 1994. 476p.

Van SOEST, P.J.; ROBERTSON, J.B.; LEWIS, B.A. et al. Methods for dietary fiber, and nonstarch polysaccharides in relation to animal nutrition. Journal of Dairy Science, v.74, p.35833597, 1991.

VARGAS, L.H.; LANA, R.P.; MÂNCIO, A.B. et al. Influência de rumensin ${ }^{\circledR}$, óleo de soja e níveis de concentrado sobre o consumo e os parâmetros fermentativos ruminais em bovinos. Revista Brasileira de Zootecnia, v.30, p.1650-1658, 2001.

Recebido: 25/10/05 Aprovado: 30/10/06 